\title{
Paideusis
}

\section{A Reflection on Arts-Based Research}

\section{Michelle Evelyn Forrest}

Volume 16, Number 2, 2007

URI: https://id.erudit.org/iderudit/1072576ar

DOI: https://doi.org/10.7202/1072576ar

See table of contents

Publisher(s)

Canadian Philosophy of Education Society

ISSN

0838-4517 (print)

1916-0348 (digital)

Explore this journal

Cite this article

Forrest, M. (2007). A Reflection on Arts-Based Research. Paideusis, 16(2), 3-13. https://doi.org/10.7202/1072576ar
Article abstract

Concerns are raised regarding the place of the arts in education, specifically as they are used in the social science context of educational research under the title 'arts-based research'. An examination of Elliot Eisner's claim that art is research concludes that, though the arts may be used for display, data, or heuristic in educational research, they are not being recognised for their distinctive characteristics. John White's critique of the theory of multiple intelligences is revisited to mitigate common claims for the arts based upon Gardner. Given the dominance of scientism in today's research climate, it is argued that the arts take their rightful place as foil to research in its quest for certainty; that they be the antagonist mode of thought called for by John Stuart Mill.
This document is protected by copyright law. Use of the services of Erudit (including reproduction) is subject to its terms and conditions, which can be viewed online.

https://apropos.erudit.org/en/users/policy-on-use/ 


\title{
A Reflection on Arts-Based Research
}

\section{MICHELLE FORREST}

Mount Saint Vincent University, Canada

\begin{abstract}
Concerns are raised regarding the place of the arts in education, specifically as they are used in the social science context of educational research under the title 'arts-based research'. An examination of Elliot Eisner's claim that art is research concludes that, though the arts may be used for display, data, or heuristic in educational research, they are not being recognised for their distinctive characteristics. John White's critique of the theory of multiple intelligences is revisited to mitigate common claims for the arts based upon Gardner. Given the dominance of scientism in today's research climate, it is argued that the arts should take their rightful place to balance research in its quest for certainty; that they be the antagonist mode of thought called for by John Stuart Mill.
\end{abstract}

\section{Introduction}

In this paper I want to consider the justifications made for art as research and the context in which these justifications are being made, and suggest where I think things should go now; namely, that the arts should take their appropriate place as foil to research in its quest for certainty. As a performing artist I cannot help but ask why art is being placed as a sub-category of a sub-category of social science research in education. Why wouldn't artists claim their place as partners with scientists and philosophers in raising questions about learning, education, and the human condition? Although these are the over-arching questions of this paper, I am torn in taking them up because I admire and appreciate the work of those who have championed art as inquiry in the social sciences. Because of them the questions regarding the relationship between art and science are renewed in a context that may shed more light than heat. Nonetheless, when I consider efforts such as those of Laurel Richardson at articulating criteria for what she calls the "new ways of writing"1 I cannot help wondering why people in the arts continue attempts at legitimising them according to scientific standards. Is this possible without conceding as irrelevant the very characteristics that make the arts distinct?

\section{Elliot Eisner's Claims for Art as Research}

The obvious place to begin is with the claims made by Elliot Eisner who has championed the use of art in education throughout his career. Upon hearing what I am to do, some may conclude that I am

\footnotetext{
${ }^{1}$ Laurel Richardson, The Art of Writing Inquiry, Lorri Neilsen, Ardra Cole, and Gary Knowles, eds., Halifax, NS: Backalong Books and Centre for Arts-informed Research, 2001, 250.

(C) Copyright 2007. The author, Michelle Forrest, assigns to Paideusis the right of first publication and educational and non-profit institutions a non-exclusive license to use this document for personal use and in courses of instruction provided that the article is used in full and this copyright statement is reproduced. Any other usage is probibited without the express permission of the author.
} 
judging Professor Eisner by inappropriate criteria since his purposes are different from mine. I admit this from the outset. I am not arguing against Eisner's claims per se so much as using them to highlight the crux of the issue I feel to be conspicuous by its absence from his work.

It was Eisner's Presidential Address at the 1993 AERA conference that set off vigorous debate about the place of the arts in educational research. ${ }^{2}$ In his address Eisner speaks about the potential for different forms of representation within educational research, pointing to the ubiquitous use of graphs, bars, and tables as an example of how forms other than words already inform research practice and how they have a synchronic character, an "all-at-onceness," difficult to grasp in language and numbers, which offer their own kinds of precision. In a 1995 paper he goes on to say that "the arts have no monopoly on art"; that "there is art in science just as surely as there is art in art". He asks if art should be conceived of according to the theories expounded in aesthetics, but he does not take up directly the implications of these theories of art; rather, he describes what he calls general features of an artwork: that it is 1) a form of representation, 2) a product displaying certain kinds of excellence, and 3) a process of "arting". He chooses to concentrate on the second, art as a product displaying certain kinds of excellence, ${ }^{3}$ which he then rephrases as "the features that works of art possess" claiming these to be three: 1) making the obscure vivid and empathy possible, 2) directing our attention to individuality and locating in the particular what is general or universal, and 3) possessing a sense of wholeness, a coherence, a kind of organic unity that makes both aesthetic experience and credibility

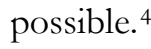

By naming and then sidestepping theories of art to talk about features of art, Eisner implies assumptions which in turn add up to an implicit theory. For example, Eisner's first general feature of art - that it is a form of representation - is a feature of many things other than art such as street signs. Though some street signs may qualify as art, this is not their defining characteristic. In discussing how art displays certain kinds of excellence, Eisner refers to art awakening us from stock responses by sometimes employing a process of defamiliarization: "the artist recontextualizes the familiar so that it takes on a new significance". Eisner is here alluding to a theory of art not mentioned in his initial references; namely, that of the Russian formalist Viktor Shklovsky, who coined the word 'ostranenia', the literal translation of which is 'making strange'. Shklovsky claimed that it is the role of the poet to make the stone stony and that to do so one first has to make it strange. ${ }^{5}$ This theory of art has much to commend it but it runs up against a problem in considering those works of art to which one goes for comfort or solace. Does this mean they are not works of art? Does it mean they may have been when first encountered but that they no longer are once the process of making strange subsides? Or, could this mean that the process of making strange is something one revisits with each re-acquaintance with the work? Suffice it to say that Eisner offers an apparently random sampling of characteristics from different theories of art. Considering his audience of educational researchers this is perhaps a good strategy. Tom Barone comments that Eisner has "never advanced arts-based research at the expense of social science." Being critical of their methods was no way to gain acceptance into their ranks. ${ }^{6}$

\footnotetext{
${ }^{2}$ Elliot Eisner, "Forms of Understanding and the Future of Educational Research", Educational Researcher 22: 7, Oct. 1993.

3 Elliot W. Eisner, "What Artistically Crafted Research Can Help Us Understand About Schools", Educational Theory 45: 1, Winter 1995, 1 - 2.

4 Ibid., 4.

5 For more on Shklovsky and defamiliarisation, see R. H. Stacy, Defamiliarization in Language and Literature, Syracuse: Syracuse University Press, 1977. As Stacy points out, various modern critics and artists have devised terms for the particular form of irony which makes difficult or strange that which is known, e.g., Dmitry Chizhevsky's "negative allegory", Leon Stilman's "perception without apperception", Kenneth Burke's "perspective by incongruity", Ezra Pound's "making strange", and Bertold Brecht's Verfremdung (2-3).

6 'Tom Barone, "From the Classrooms of Stanford to the Alleys of Amsterdam: Elliot Eisner as Pedagogue", Aesthetics, Politics, and Educational Inquiry, New York: Peter Lang, 18.
} 
I point out certain problems with Eisner's 1995 essay to demonstrate that there is a history of writing in the philosophy of art, the apparent dismissal of which seems counterintuitive. Why not draw from aesthetics more specifically in making claims about art in or as inquiry? Many of those who have objected to the approach of Eisner and others in using art as method in educational research have done so because, like me, they do not understand why art needs to be justified according to criteria of social science research. How much of artistic process in social science is easily assimilated, and how much that is represents that which makes art distinctive from other pursuits? ${ }^{7}$

In his response to Eisner's 1995 essay, D.C. Phillips sorts out Eisner's claims by dismissing some as non-controversial; namely, that "the arts should be reflected more than they are in the 'display' of research." Phillips considers that such a claim "reflects good educational sense". ${ }^{8}$ This takes us back to Eisner's point that the arts have no monopoly on art. Certainly the careful and expert crafting of anything can be said to be artful and the more attention given to artistically displaying research findings, the more likely their dissemination will be successful. Here I use 'artistry' in the sense of striking an appropriate balance between a work's substance and the form in which it is presented. In this sense many research papers could be said to be artful; though one would still not call them art. In addition to Eisner's claim that research should be artistic in its display, I would add another non-controversial point: that artwork may well serve as the raw data for social science research as it does in some phenomenological studies and in the sociology of art.

Phillips defeats Eisner's controversial claims that art is research by pointing out that Eisner construes the terms 'research', 'truth', and 'art' so broadly that, though these claims become valid, they are unexceptional.' In his definition of 'research', Eisner glosses over fundamental philosophical and logical difficulties, according to Phillips. For example, by saying that the term 'truth' should not be restricted to what one can claim, Eisner is not taking into consideration that in the logical sense 'true' and 'false' only apply to propositions, not to things or states of affairs. To say that a work of art expresses a great truth implies that the speaker can formulate this truth in a proposition and support it with evidence. ${ }^{10}$ Ultimately, Phillips sees Eisner's attempt to judge art by social science criteria as a category mistake, although he grants that art can be called 'inquiry' according to a broad definition of the term like that of Dewey.

By 1997 Eisner refined his claims by referring to art in research as 'alternative forms of data representation' 11 and he articulated the promise of alternative forms in five points which I summarise as follows: educational research needs new artistic tools or media (Eisner uses the terms interchangeably) because they offer authenticity and "productive ambiguity" leading to new questions, and they activate wider varieties of human intelligence. ${ }^{12}$ Eisner's claim that research needs and/or should be open to new tools is not controversial. Research is continually employing new tools, demonstrated vividly by the flourishing of cognitive science in the wake of such technology as magnetic resonance imaging. Eisner's point that artistic data presentation offer authenticity and 'productive ambiguity' could be controversial; however, his assertion that "tools, among other things, are also heuristics" makes his claim non-controversial. Heuristics are used in the sciences to stimulate investigation within the parameters of experimental methodology, not as a stand-alone method. In

\footnotetext{
${ }^{7}$ Jane Piirto frames the question this way: "What does the very nature of poetry have to contribute to educational research?" (444). Piirto offers a convincing argument for the need to set stringent aesthetic standards for artsbased research. See "The question of quality and qualifications: writing inferior poems as qualitative research", Qualitative Studies in Education 15: 4, 2002.

${ }^{8}$ D.C. Phillips, “Art as Research, Research as Art”, Educational Theory, 45: 1, Winter, 1995.

${ }^{9}$ Ibid., 73.

${ }^{10}$ Ibid., 76.

${ }^{11}$ Elliot W. Eisner, "The Promise and Perils of Alternative Forms of Data Representation", Educational Researcher 26: 6, 1997, 4-10.

12 Ibid., 8.
} 
addition, the heuristic method is already recognised within qualitative research, and to say that the arts and humanities have something to offer hermeneutics is to state a truism.

What is controversial, however, is for the research community to accept art as art. Eisner recognises this in describing one of the perils: the fact that art can lack referential precision, which is a requirement of conventional social science in its goal to reduce ambiguity. ${ }^{13} \mathrm{He}$ says that although the ambiguity of art can be a source of insight, its peril is the problem of interpretation. "No consensus is possible. The data mean whatever anyone wants them to mean; or worse, no [one] knows what they mean."14 Instead of taking up the controversial claim and arguing for ambiguity, Eisner cautions artsbased researchers to recognise the need for interpretation and "describe the context in which the results of research are to be presented." Although Eisner says that he supports the arts in research in their potential to explore "the edges of possibility," he reminds readers that no one likes to be lost.

It seems then, that, although Elliot Eisner claims that art is research, he does so using such a broad definition of research that his claim is benign; it offers no real challenge to the dogmatic materialist view of reality dominant in educational research. ${ }^{15}$ He concedes that the need in social science for referential precision must be recognised as an essential protocol, and that art must be contextualised. He also warns arts-based researchers against "a tendency to allow aesthetic considerations [to] trump the need for epistemic orientation to disclosure" implying again that he wants art in, but not as art. Those of its characteristics that overlap with research are acceptable; those that don't are either out or require interpretation.

\section{White's Critique of Gardner's Theory}

There is a recurrent though tangential theme in Eisner's position that needs to be addressed; that is, his allusions to Gardner's theory of multiple intelligences. I agree with Eisner that Gardner's theory has served to open up the school curriculum to the potential of alternative modes of expression. My belief that the arts and the aesthetic are foundational to learning and education is strong too; but, I side with John White in his concern over adopting Gardner's theory. What exactly are Eisner and other educators accepting in endorsing Gardner's theory? In tracing the threads of Eisner's references to MI theory, I find that he stops short of resting his argument for alternate forms of data representation on it; for example, he says: "If intelligence can be defined, as Olson (1988) suggested, as skill in a medium, then the use of different media for the creation of research is a way to activate different varieties of intelligence."16 Eisner's assumption that intelligence has varieties that are activated by different media suggests Gardner's definition of intelligence as "a biopsychological potential to process information that can be activated in a cultural setting." 17 It is understandable that Eisner would find Gardner's theory useful since part of his own project has been to direct attention to the cognitive in art rather than focussing on the arts as driven only by emotional and creative forces. ${ }^{18}$

In his 2004 contribution to a special issue of the Teachers College Record devoted to Gardner's theory of multiple intelligences, Eisner hedges again on accepting the premise of MI theory, wondering whether its locations in biological and behavioural theory "are as identifiable as Gardner (1983)

\footnotetext{
${ }^{13}$ Ibid., 9.

14 Ibid.

15 As Mary Midgley puts it, "[t]he trouble [with materialism] is quite simply that the Cartesian concept of matter, which was framed in the first place as a contrast to mind, cannot be extended to take in its opposite without losing its meaning." See Science and Poetry, London: Routledge, 2001, 12.

${ }^{16}$ Eisner, 1997, 8.

${ }^{17}$ Howard Gardner, Intelligence Reframed: Multiple Intelligences for the 21 ${ }^{\text {st }}$ Century, New York: Basic Books, 33-34.

${ }_{18}$ P. Bruce Uhrmacher, "Elliot Eisner" in J. A. Palmer (ed.) Fifty Modern Thinkers on Education. From Piaget to the present, London: Routledge, 2001, 248.
} 
suggests they are." Eisner lauds its effects for schooling as an antidote to the dominant cult of efficiency with its focus on homogenising outcomes in the attainment of prespecified goals. ${ }^{19} \mathrm{He}$ commends Gardner for the effects his theory has had in cultivating diversity in schools, but he sees as ironic the fact that "schools are driven by policies that provide increasingly little space to pursue the vision that multiples intelligences adumbrates." 20 Eisner celebrates Gardner for giving us not only a theory, but "a generous image of the varieties of human capacity" and "a new frame of reference for reflecting on the nature of mind". 21

In assessing MI theory as scientific, Jie-Qi Chen concludes that Gardner's theory is like many others in the social sciences that are rarely proved or disproved decisively. The value of MI theory "depends on the contribution it makes to understanding and to practice in the field". ${ }^{22}$ Though Gardner's theory has undoubtedly proven useful in opening minds to the wide range of diversity in today's school populations, the useful effects of a theory are not sufficient to justify its claims. As for the role of MI theory in supporting more emphasis on the arts in education, Klein points out that balanced programming is not essentially related to MI theory, and that arts education can be justified otherwise: on the basis of 'its role in providing enjoyment, cultivating students' aesthetic sensibilities, or providing insights into how other people experience the world." 23 Since Eisner's claims are influenced by MI theory, ${ }^{24}$ and considering the role MI theory plays in recent claims for the importance of the arts in education, ${ }^{25}$ it is worth revisiting a thorough critique of it.

John White asks if Gardner's multiple intelligences add up. He begins by distinguishing between the general claim that intelligence takes many forms and the particular version this claim takes in the theory of MI. Many teachers and educators have latched on to MI theory because of this first claim, says White. They recognise that students with diverse abilities need to understand that intelligence is not limited to the nimbleness in abstract logical reasoning tested by conventional IQ tests. White points out that "Aristotle had distinguished the merely clever person, who is good at adapting means to ends whether the ends are desirable or not, from the practically wise person, who makes sure the ends are good to start with." In other words, intelligence is only one of the criteria for judging a person's capacities. White's following remarks are helpful in summing up the philosophical tradition to which he alludes:

Intelligent action has to do with the flexible adaptation of means in the pursuit of one's goals and there are as many types of human intelligence as there are types of human goal. Intelligence is displayed in countless different ways. ${ }^{26}$

In order, then, to argue that diversity ought to be recognised and planned for in schooling, one need only rely on Aristotle and on common sense, which quite rightly assumes there can be intelligent action

${ }^{19}$ Elliot W. Eisner, "Multiple Intelligences: Its Tensions and Possibilities", Teachers College Record 106: 1, Jan. 2004, $32-35$.

${ }^{20}$ Ibid., 34.

${ }^{21}$ Ibid., 39. I would suggest that Israel Scheffler's Of Human Potential (1985) and Gilbert Ryle's The Concept of Mind (1949) offer these things and more.

${ }^{22}$ Jie-Qi Chen, “Theory of Multiple Intelligences: Is It a Scientific Theory?”, Teachers College Record 106: 1, Jan. 2004, 22.

${ }^{23}$ Klein, P., "Rethinking the multiplicity of cognitive resources and curricular representations: alternatives to 'learning styles' and 'multiple intelligences"', Journal of Curriculum Studies 35: 1, 2003, 61.

${ }^{24}$ Efland, A.D., Art and Cognition, New York: Teachers College Press, 2002, 62. According to Efland, Eisner

(1982) "wrote as an educational theorist and critic rather than as a psychologist, although his argument was couched largely in the language of cognitive psychology."

${ }^{25}$ Klein, 61.

${ }^{26}$ White, J., Do Howard Gardner's multiple intelligences add up? London: Institute of Education, University of London, 1998, 60. White cites Gardner's Frames of Mind, London: Heinemann, 1983, 60. 
across an infinite spectrum of applications. White's definition of intelligence as the flexible adaptation of means to ends avoids the reification Gardner and other psychologists fall into by assuming that 'intelligence' is something in humans, as opposed to a term to describe effective human adaptations to environmental conditions. White goes on to say that:

Gardner has admitted the great number of different ways in which intelligence is manifested, yet has sought to regiment this variousness, to corral it within a small number of categories, within what he has called his 'charmed circle of intelligences'27

If one needs a rationale for claiming that intelligence takes many forms, it is understandable that, in an age of scientism, a new social science theory would garner more attention than Aristotelian philosophy. We will return later to the effects of scientism.

In assessing the particular claims of MI theory, White challenges it with three main critiques. First, he questions the developmentalism central to Gardner's theory; i.e., that the unfolding characteristic of the biological realm is also found in the mental realm. There are two problems with developmentalism: 1) although innate human capacities change through a process of differentiation dependent upon social influences (e.g., says White, the ability to move one's limbs becomes specified into the ability to do the tango), our capacities do not unfold like a seed, which has within it the power to unfold into more complex stages; and 2) the growth metaphor applied to human mental capacities implies a ceiling or limit to development as in a fully-grown human body not being able to grow any further, and this concept of intelligence having mental ceilings has already been thoroughly critiqued. In short, White raises serious problems in identifying mental counterparts to biological growth. ${ }^{28}$

Second, White turns to Gardner's heavy reliance on aesthetic criteria in delineating the specific characteristics of most of his intelligences. This has been very influential in the theory's appeal to schools and to artists and art educators. Gardner's aesthetic criteria are dependent upon the theory of his mentor, Nelson Goodman and his cognitive account of the arts as symbols, a theory with its own problems in that art has been shown not to be symbolic in the way Goodman describes. Goodman claims that art symbols refer to things outside themselves just as words or mathematical symbols do; but, as his critics have pointed out, this would imply that art symbols would be translatable as the word 'cat' is translatable into the German 'Katze' referring to the same thing. Goodman also claims that the point of aesthetic experience, like that with other symbol systems, is to attain knowledge of the world; but, this does not account for the fact that people return to the same artwork over and over to relive past enjoyment. In short, the basis for Gardner's aesthetic considerations, upon which rest seven of his intelligences, are based upon a theory of art with questions outstanding. ${ }^{29}$

White credits Gardner, in his second edition of Frames of Mind, with taking into consideration Aristotle's distinction between the practically wise person and one who is merely clever and its implication that intelligence in itself is no guarantee that a person will put means to good ends. This, says White, brings Gardner's theory closer to the everyday concept of intelligence. White sums up by saying that if Gardner "had subjected his developmentalist and symbol-theory assumptions to philosophical critique, the original theory probably could not have even reached the drawing board." 30 White then offers what he calls "the everyday idea of multiple intelligences" as an alternative, and he outlines a similar phenomenon of theory adulation that happened with Paul Hirst's 'forms of knowledge' in the 1960s and 70s. ${ }^{31}$ Both theories were widely misconstrued as prescriptions for teaching and curriculum design.

\footnotetext{
27 Ibid.

${ }^{28}$ Ibid., 8-11.

${ }^{29}$ Ibid., 12-14.

30 Ibid., 21.

31 Ibid., 20-21.
} 
As I see it, the irony in the remarkable success of Gardner's theory is that, in his efforts to offer something broader than the psychometric notion of intelligence as IQ, he has succeeded in further entrenching the idea of intelligence as a cognitive function, thereby leaving new generations of teachers and educators steeped in the culture of testing, predicated upon products and the perceived outcomes they represent. A victim of his own success, Gardner emphasises that he "never had a desire to impose MI ideas on any school or community." 32 He applauds some school-based applications of MI theory and is horrified by others. ${ }^{33}$ Although it is true that, partly due to the influence of MI theory, schools are now more open to various forms of representation, these are thought to directly correspond to cognitive functions. As Klein points out, the neurological evidence suggests a cognitive architecture messier than MI's eight modules; ${ }^{34}$ one that may not even depend upon the long-favoured construct of intelligence. ${ }^{35}$ Eisner finds it ironic that though schools embrace the cultivation of diversity that MI theory promotes, they are driven by policies counter to the vision that MI theory represents. ${ }^{36}$ I would suggest that this is hardly surprising since MI theory, like other theories driving school policy-making, possesses the 'evidence-based' aura that feeds prevalent scientistic attitudes.

What are we to make of Eisner's arguments for accepting arts-based research? I agree with Phillips that Eisner's efforts to raise the profile of the arts in education and curriculum are highly commendable. I also agree with Phillips that most of what Eisner claims regarding the usefulness of art as alternative form of data representation is non-controversial. Using the arts in data representation, as raw data, and as heuristics in social science is already happening. The controversial claim that art is research has been made by Eisner by broadening these categories to the point where their distinctiveness no longer matters. It is to this that I object. What is the point of sneaking art in the back door of the social sciences if, in doing so, one does not celebrate what makes art distinctive. What remains, then, is two-fold: to position the arts in relation to the dominance of the sciences and to suggest how the arts can function as a fully-fledged member of education as a scholarly pursuit.

\section{Scientism and the Two Cultures}

Many theorists have attempted similar projects to that of Eisner in attempting to counteract attitudes reflected by what has been called 'scientism'. Habermas defines scientism as "the conviction that we can no longer understand science as one form of possible knowledge, but rather must identify knowledge with science." Comte's positivism drew from rationalism and empiricism to "strengthen science's belief in its exclusive validity after the fact, instead of to reflect (reflektieren) on it, and to account for the structure of sciences on the basis of this belief." 37 We now live in an age of 'scientism'. The incommensurable success of technology as a way of managing human life is taken to imply that the natural sciences are the arbiters of knowledge claims and that claims from other disciplines are justified only to the extent that they strive to make themselves 'scientific'. I am not claiming that scientists see science this way, though some may; only that, in general today, science is viewed as the source of knowledge. ${ }^{38}$ The dominance of this view constitutes an ideology of scientism; whereas, the sciences

\footnotetext{
32 Howard Gardner, "Audiences for the Theory of Multiple Intelligences”, Teachers College Record, 106: 1, Jan., 2004, 215.

33 Ibid., 215-216.

34 Klein, 52.

35 Ibid., 62.

${ }^{36}$ Eisner, 2004, 34.

37 Jurgen Habermas, Knowledge and Human Interests (1968), J. J. Shapiro, trans., Boston: Beacon Press, 1971, 4-5.

38 Mary Midgley (2001) claims that many people today "have a suspicion, welcome or otherwise, that the arts are mere luxuries and science is the only intellectual necessity. It seems to them that science supplies all the facts out
} 
themselves, like the arts and humanities, are fields of inquiry governed by particular epistemological practices. ${ }^{39}$

The dualism perpetuated in social science research and its pedagogy ${ }^{40}$ is that between positivist and interpretivist methodologies. As St. Pierre and Roulston point out, though qualitative research straddles this divide it retains positivist features, such as the idea that larger quantities of data are better than smaller quantities, and richer, thicker descriptions yield truer representations of lived experience. ${ }^{41}$ As we have seen, the most notable champion of arts-based research also admits ultimate legitimacy to positivist essentials such as referential precision and the reduction of ambiguity. It would seem, then, that the efforts of arts-based researchers to justify art as method in qualitative educational research are like those of Sisyphus pushing the boulder uphill. Despite any progress made, the weight of positivist assumptions keep pushing them back. Their efforts have succeeded insofar as arts-based research is defined as educational research that uses the arts as a supplement within an over-arching social science methodology. I disagree, however, that Eisner's has been the best strategy for eking out a place for art as art in education. This brings me to the famous debate referred to as 'the two cultures.' I will now retrace some of its lineage in an attempt to arrive at an alternative strategy to that of Eisner and his followers.

When C. P. Snow gave his famous Rede lecture entitled "The Two Cultures" in 1959 he was fighting for recognition within the academy for what we now call 'research'. At that time the literary intellectuals and the ideal of a classical education which they represented were the dominant forces in English-speaking academia and anything as prosaic as applying technologies to the world's problems was seen as inappropriate to the pursuits of a 'gentleman'. The antecedents of Snow's debate with the literary critic F.R. Leavis can be traced to the tensions in nineteenth century and, as Stephan Collini points out, it should be recognised that the geneology of this debate is a product of the British institutions within which education and research were conducted. ${ }^{42}$ In 1840 John Stuart Mill published his essay on Coleridge, a companion piece to his essay two years earlier on Jeremy Bentham. Mill contrasts the two nineteenth century thinkers, whom he considered essential reading for anyone interested in understanding the thought and influences of the times in England:

By Bentham, beyond all others, men have been led to ask themselves, in regard to any ancient or received opinion, Is it true? and by Coleridge, What is the meaning of it? The one took his stand outside the received opinion, and surveyed it as an entire stranger to it: the other looked at it from within, and endeavoured to see it with the eyes of a believer in it; to discover by what apparent facts it was at first suggested, and by what appearances it has ever since been rendered continually credible - has seemed, to a succession of persons, to be a faithful interpretation of their experience. ${ }^{43}$

of which we build (so to speak) the house of our beliefs. Only after that house is built can we - if we like - sit down inside it, turn on the CD player and listen to some Mozart or read some poetry" (22).

${ }^{39} \mathrm{I}$ am grateful to an anonymous reviewer for offering this distinction.

40 For an philosophical examination of a popular textbook on educational research see Darrell Patrick Rowbottom and Sarah Jane Aiston, "The Myth of 'Scientific Method' in Contemporary Educational Research", Journal of Philosophy of Education 40: 2, 2006.

41 Elizabeth Adams St. Pierre and Kathryn Roulston, "The state of qualitative inquiry: a contested science", International Journal of Qualitative Studies in Education 19: 6, Nov.-Dec. 2006, 677.

42 Stefan Collini, introduction to C. P. Snow, The Two Cultures (1959), Cambridge: Cambridge University Press, 1993, xi.

${ }^{43}$ Mill on Bentham and Coleridge, introduction by F. R. Leavis, London: Chatto and Windus, 1967, 99-100. 
Mill credits Coleridge with saying that "every one is born either a Platonist or an Aristotelian". According to Mill, every Englishman of his day was either a Coleridgian or a Benthamite; ${ }^{44}$ that is, either an intuitionist or a utilitarian. Mill's characterisation of the contrast between Coleridge and Bentham in the questions: What is the meaning of this? as opposed to Is it true? are useful today in discussing the difference between the distinctive characteristics of art and science. The former explores meaning in the way in which something is conceptualised, while the latter assesses its subject according to predesigned methods for establishing validity. Both of these questions are important and reliant on one another. The salient point, for our purposes, is made by Mill:

For, among the truths long recognised by Continental philosophers, but which very few Englishmen have yet arrived at, one is, the importance, in the present imperfect state of mental and social science, of antagonist modes of thought: which, it will one day be felt, are as necessary to one another in speculation, as mutually checking powers are in a political constitution. A clear insight, indeed, into this necessity is the only rational or enduring basis of philosophical tolerance; the only condition under which liberality in matters of opinion can be anything better than a polite synonym for indifference between one opinion and another. ${ }^{45}$

Regarding the positioning of the arts in education, how can our current conditions be ameliorated by embracing the importance of antagonist modes of thought? What is the place of art in this process? If art in educational research is an heuristic within a positivist framework, its checking power is not recognised as such.

If the reader feels that no checks are necessary against the scientistic way of thinking in education, she need only speak to teachers to realise how much stress is now placed upon them under the name of 'evidence-based research'. Nova Scotia is definitely feeling the effects of scientism in education. ${ }^{46}$ One need not look far to see the roots of this influence. As defined in the 2002 United States No Child Left Behind Act (Public Law No. 107-110), the highest standards for educational research are scientifically based or evidence-based, meaning research that is "replicable, generalizable, empirical and preferably experimental" (Section 9101 [37]). ${ }^{47}$ In their introduction to a recent issue of the International Journal of Qualitative Studies in Education on the state of qualitative inquiry, St. Pierre and Roulston believe there is serious reason for concern.

The federal [US] government is funding a new organization that focuses on causal, experimental research, bypassing AERA. AERA is now in the business of producing standards for researchers. Given the politics of SBR [scientifically based research], our students are confused and wonder whether they should do qualitative work. It is not that all this is necessarily bad, but the effects of these recommendations, descriptions and practices are already being taken up and put to work in simplistic and reductive ways. ${ }^{48}$

The irony of scientism is that, although in our age most scholarship no longer defers to divine authority, science has been so successful in supplanting God and all versions of idealism that it has

\footnotetext{
${ }^{44}$ Mill does concede, however, that the essentials of Coleridge's doctrine had been anticipated by the "great Germans of the latter half of the last century, and was accompanied in it by the remarkable series of their French expositors and followers" (102-103).

45 Ibid., 104.

${ }^{46}$ Using the descriptor 'evidence-based' in the Government of Nova Scotia Education Department search engine resulted in 102 hits including phrases with 'evidence-based' before each of the following terms: health education, best practice, policies, information, strategy, library. (See www.ednet.ns.ca.)

${ }^{47}$ As cited in St. Pierre and Roulston, 2006, 674.

${ }^{48}$ Ibid., 679.
} 
itself become the new religion. Belief in science as "supra-historic and neutral" 49 amounts to a denial that belief has anything to do with this allegiance. According to Mary Midgley, "all science grows out of philosophical thinking - out of the criticism of imaginative visions" and science

takes that criticism for granted and always continues to need it. [This] is why the vision of an omnicompetent science - a free-standing, autonomous skill with a monopoly of rationality that does all our thinking for us - is not workable. . . . All science includes philosophic assumptions that can be questioned and those assumptions don't stop being influential just because they have been forgotten. ${ }^{50}$

It is the arts and humanities that remind us of the philosophical questions upon which our assumptions rest. Though philosophy is there to keep science honest and reflective, the arts are up-front and personal. As antagonist to certainty, the arts confuse, provoke and take us aback. As Hamlet put it: "The play's the thing wherein I'll catch the conscience of the king" (II.ii.616-617). Mill called for antagonist modes of thought that are mutually checking. Another way of seeing this is as the play of difference in which "[d]ifference is not a thing, it is a process. It unfolds - or better, it is an unfolding (and a folding, and a refolding)." 51 When the classical curriculum was the protagonist in the academy, C.P. Snow stormed on stage with science as antagonist. Now that the tables are turned, the arts serve this role.

\section{Conclusion}

In 2002 René Arcilla ignited a debate with his question "Why aren't philosophers and educators speaking to each other?" 52 The range of responses to his question went the gamut from agreement to dismissal to parody. ${ }^{53}$ His concern over the place of philosophy in light of the dominance of the social sciences parallels the case of the arts in education. There is no doubt, as Arcilla points out, that the social sciences "with their confident positivism" have been hugely successful in "framing social problems for the purposes of policy reform." 54 So, is the best path for philosophers of education to morph into theorists of different stripes and follow the other social sciences out of philosophy altogether? Arcilla's other suggestion is the one he seems to prefer; that is, that we focus on Dewey's sense of the central task of philosophy, in particular as it relates to one of the philosophy of education's conventions: the maturing of one's epistemic relation to ideas into an attitudinal relation to problems in society. ${ }^{55}$ This convention manifests itself in the practice of skeptical questioning and, claims Arcilla, skepticism is the philosophical contribution to education not easily assimilated into the social sciences.

This is, in my view, the role of antagonist to which Mill refers; that of balancing the power of the dominant ethos. In his introduction to Snow's "The Two Cultures", Collini describes the pressure the sciences are under to retain their integrity:

$49 \mathrm{~J}$. Bleicher, The Hermeneutic Imagination: Outline of a Positive Critique of Scientism and Sociology, London: Routledge, $1982,3$.

${ }^{50}$ Midgley, $36-37$.

51 Todd May, Gilles Deleure. An Introduction, Cambridge: Cambridge University Press, 2005, 24.

${ }^{52}$ René Arcilla, "Why Aren't Philosophers and Educators Speaking to Each Other?", Educational Theory 52: 1, $2002,1-11$.

${ }^{53}$ Educational Theory 52: 3, 2002.

54 Arcilla, 9.

55 Arcilla, 5. 
In practice, much of what is commonly regarded as 'science' has to be understood at the end of the twentieth century less as disinterested enquiry and more as part of the commercial strategies of drug companies, aerospace industries, and the like. ${ }^{56}$

These are fighting words, no doubt; but, the reality has become difficult to ignore. Will the insinuation of the arts into educational research serve the necessary purpose of introducing a curative dose of skepticism? I fear not. I am with Eisner one hundred percent in his resistance to the cult of efficiency and its insidious effects; but I think artists in education need to consider a bigger picture. Though schools most definitely need the arts to balance the sciences in what Dewey has called their 'quest for certainty', ${ }^{57}$ the same is true in the academy. I would suggest that artists in education consider taking their distinctive place in the field and thereby supporting the skeptical project not easily assimilated into science, social or otherwise.

Tangled scenes of life are made more intelligible in esthetic experience: not, however, as reflection and science render things more intelligible by reduction to conceptual form, but by presenting their meanings as the matter of a clarified, coherent, and intensified or "impassioned" experience. ${ }^{58}$

\section{About the Author}

Michelle Forrest began her professional life as a singer of opera, oratorio, and concert repertoire. She teaches philosophy of education, aesthetics, media and the arts to pre-service and in-service teachers at Mount Saint Vincent University in Halifax. She writes on the arts and openness, the place of the arts in society and education, media bias, and collaborative scholarship. She belongs to two research collectives employing diverse means of representation: The $(1+1+1)$ Collective and CORE (Collaborating on Research in Education). E-mail: michelle.forrest@msvu.ca.

\footnotetext{
${ }^{56}$ Collini, lxv - lxvi.

${ }^{57}$ John Dewey, The Quest for Certainty: A Study of the Relation of Knowledge and Action, London: George Allen \& Unwin, 1930.

${ }^{58}$ John Dewey, Art as Experience (1934), New York: Perigee Books, 1980, 290.
} 